\title{
ENTRE LA DEVOCIÓN Y LA EDUCACIÓN: UN EJEMPLO DE LITERATURA MODELADORA DEL COMPORTAMIENTO FEMENINO (1).
}

\section{GLORIA ESPIGADO TOCINO \\ Universidad de Cádiz}

Textos ha habido que, desde antiguo, se han dirigido específicamente a las mujeres con intención de instruirlas y adoctrinarlas en sus particulares deberes sociales y religiosos. Podríamos citar a Juan Luis Vives, De la instrucción de las mujeres cristianas (1523), al famoso libro del Abad Fenelón, Sobre la educación de las niñas (1687) y a la, no menos popular entre las españolas, obra de Fray Luis de León, La perfecta casada (1583), entre otros muchos. Sabido es, también, que ya en el Concilio de Trento (1545-1563) se enuncian las bases en pro de favorecer una educación cristiana para la que se consideraba iba a constituir en el orbe católico la principal figura de adoctrinamiento dentro del seno familiar (2).

Desde entonces, estando cada vez más asentada la idea de que la educación universal compete también a las mujeres, a todas las mujeres, puesto que dentro de la familia se la reconoce como primera instancia educadora, con cierto retraso con respecto a la educación de los niños, comienzan también a darse las primeras actuaciones públicas, municipales, en favor de la educación gratuita de las niñas, loque en Cádiz no ocurre antes de 1842, fecha en la cual el Ayuntamiento se hace cargo de la escuela femenina sostenida por la Sociedad Económica de Amigos del País. Con anterioridad a esta fecha, las únicas iniciativas de tipo filantrópico y caritativo están representadas por la fundación que una piadosa dama, Doña María de Arteaga y Verovia, hiciera en 1787. para educar a las gaditanas pobres bajo la advocación del Carmen y que dependería de patronato catedralicio (3) y aquélla que efectuaran las Damas de la Sociedad Económica Gaditana en 1827, de la que nos vamos a ocupar en estas páginas.

Antes de seguir avanzando, resulta adecuado contextualizar esta iniciativa dentro de un entorno de escasos progresos legales en favor de la educación femenina. En este sentido habrá que recordar que el proyecto educativo que el ribuno Manuel José Quintana elaborara durante el periodo constitucional doceañista prescribía una educación privada, doméstica, para la mujer. Por su parte, la Ley de Instrucción Primaria de julio de 1838, al mismo tiempo que obligaba al mantenimiento de una escuela para varones en todo pueblo con más de 100 vecinos, recomendaba, al final de su articulado, la conveniencia de erigir «donde quiera que los recursos lo permitan» escuelas para niñas, así como para párvulos y adultos. No será hasta la Ley de Instrucción Pública de 9 de septiembre de 1857, más conocida como Ley Moyano, cuando se establezca la obligatoriedad de escolarización para todos los niños, sin distinción de sexos, entre los 6 y los 9 años. Si éste es el estrecho margen que el Estado liberal arbitra para la formación elemental de las españolas, es posible imaginar lo vedado que 
resultaría procurarse una instrucción de índole superior, y a tenor de esto último es preciso recordar que legalmente la universidad en España no se ofrece, sin ningún tipo de trabas, a las mujeres hasta 1910. No obstante, como nota positiva, en el mismo año en que se publica el texto que es objeto de nuestro comentario, la Real Orden de 27 de febrero de 1837 franquea la entrada de la Biblioteca Nacional al sexo femenino (4).

Volviendo al caso gaditano y a las fechas que nos ocupan, en 1826 la Sociedad Económica de Amigos del País se había planteado, por fin, la necesidad de disponer de un centro de enseñanza para niñas, toda vez que la decadencia económica, representada por el mal cariz que venía observando el comercio y los negocios en aquellos años, hacía imposible que los padres afrontaran la educación, se entiende doméstica, de sus hijos (5). La jurisdicción de la escuela recaería en la Junta de Damas, filial femenina de la Gaditana, organizada, tras algún intento fallido anterior, en ese mismo año bajo la presidencia de la Marquesa de Casa-Rábago, estableciéndose un marco normativo para el funcionamiento de la escuela (6). Nacida con el propósito expreso de ofrecer educación literaria gratuitamente a las niñas gaditanas, se proponía, además, instruirlas en las «labores propias de su sexo» en expresión de la época. Una vez abierta, la escuela conocería serias dificultades económicas que amenazaron sistemáticamente su existencia, hasta que en 1842 , ante la disyuntiva de ver desaparecer este centro de instrucción, el Ayuntamiento se hará cargo del mismo, aunque respetando la acción tutelar de las Damas de la Sociedad en éste y en los demás centros femeninos y de párvulos que se crearán a partir de entonces (7)

Los problemas de financiación van a contrastar con el éxito de matrícula manifestado desde el momento de su apertura. Justo al año de funcionamiento, la escuela tendría que mudarse de local por falta de espacio, trasladándose de la calle Empedrador a la del Beaterio, en dependencias solicitadas al Obispado, lugar en que la encontramos en el momento en que se edita el texto que es objeto de nuestra investigación (8). Así, las 60 alumnas que abren el establecimiento pasan de la centena cuando se acuerda su traslado y en la fecha que analizamos son 143, pero todavía seguirá creciendo hasta alcanzar el número de 300 alumnas en vísperas del paso a la jurisdicción municipal (9).

Aprovechando su existencia, Católica Infancia, o visitas a la Academia Gratuita del Beaterio, es la obra anónima de un Amigo de la Academia, según firma del libro editado en Cádiz, en la Imprenta de la Viuda e Hijo de Bosch en 1837. En éste, la escuela, modélica en su funcionamiento, es utilizada por el que se dice «amigo de la Academia» para cumplir con sus objetivos educadores, que persigue, antes que nada, salir al paso de la falta de una instrucción religiosa sólida que atestigüe las creencias y los dogmas en pruebas irrefutables de razón (10). La endeblez de esta formación en la Doctrina se traduce, según su autor, en una descatolización temprana en el momento en que los malos ejemplos y los libros perniciosos hacen acto de presencia ante mentes inmaduras que no han recibido «motivos de credibilidad y pruebas convincentes para seguirla». El 
autor piensa que el hecho de que el credo católico haya monopolizado las creencias de los españoles, sin que las circunstancias hayan llevado a éstos a tener que combatir la existencia de otras religiones, ha relajado a la feligresía y ha tenido el efecto de producir «descuido» y «confianza», actitudes que en las actuales circunstancias resultaría muy peligroso mantener.

Esta inquietud hay que ponerla en relación con la irrupción del ciclo revolucionario burgués que inaugura la contemporaneidad que sin ser, en modo alguno, ateo, pretende, sin embargo, una suerte de reformas sociales y políticas que no pueden por menos que afectar fundamentalmente a la estructura eclesiástica heredada del Antiguo Régimen. La abolición del privilegio estamental, dentro de una sociedad de iguales; la supresión de instituciones de control ideológico como la Inquisición y la abolición de prácticas fiscales como el diezmo; la desvinculación de tierras de las manos muertas a fin de consagrar la nueva sociedad de propietarios que nace, la subsiguiente desamortización eclesiástica, con las derivaciones deseadas de exclaustración y reducción del clero regular, tenido por menos útil y, finalmente, la adopción de una política de protección desde el Estado confesional, que pretende instrumentalizar al credo religioso y a sus ministros de manera que la mansedumbre cristiana predicada sirva de contención a la protesta popular, son esencialmente las reformas que promueve el nuevo poder liberal.

Tras continuos vaivenes y reveses sufridos por este nuevo modelo de relación Iglesia-Estado, en virtud de las respuestas contrarrevolucionarias protagonizadas por el absolutismo fernandino, la muerte del monarca y la difícil coyuntura sucesoria perfilan el triunfo definitivo de esta manera de afrontar el poder político, no sin que una parte importante de la jerarquía eclesiástica, respaldada por las consignas emitidas por el sucesor de San Pedro, más cierto sector del clero bajo y de la opinión católica, en algunos casos identificada con la opción continuista carlista, defiendan hasta sus últimas consecuencias sus posiciones autónomas ante un poder absorbente. Especialmente críticos fueron los años que median entre 1835-1843, desde la subida al poder del moderado Martínez de la Rosa hasta el final de la regencia esparterista, donde los ministerios Toreno, Mendizábal, Istúriz, Calatrava, etc., terminan por expugnar las defensas eclesiásticas, imponiendo el modelo reformista que hemos descrito (11).

De sobra nos es conocido que la ciudad de Cádiz, desde que la erigieran en bastión revolucionario aquellos liberales del año doce y renovara su compromiso reformador en los tiempos difíciles del Trienio, se había manifestado como un foco de inquietud exaltada durante las dos regencias que anteceden a la subida al trono de Isabel II (12). Por ello, la imagen idílica que nos presenta el autor de estas líneas choca con la realidad turbulenta que sabemos se dio en aquellos años, de modo que exponer «el carácter benéfico que ha distinguido siempre a sus habitantes y la apacibilidad que la ha hecho apreciable sobre las demás poblaciones, donde por desgracia todo es terror, perturbación, enconos, insultos y venganzas en nuestros días», hasta el punto de señalarse en 
la prensa periódica por su «punto de quietud y sosiego» como «el paraíso de nuestra España», fuera de toda sospecha sarcástica, debe ser interpretado como un ferviente deseo de que la vida ciudadana discurra por las sendas pacíficas tiempo ha abandonadas (13).

La cautela en la crítica política es de todo punto aconsejable en tiempos de inestabilidad y guerra civil como los que corren, de manera que no encontraremos referencias directas a las partes en conflicto (por ejemplo no existe alusión alguna al carlismo o al liberalismo, ni a ninguna de las medidas tomadas por los distintos ministerios, como tampoco se alude a la posición hostil del Vaticano). La prudencia es el rasgo que caracteriza al autor, no por casualidad es anónimo el escrito, al que resulta difícil identificar en virtud de sus tímidos posicionamientos políticos. La única opinión arriesgada que encontramos nos hacen dudar de que sea absolutamente contrario a todo tipo de reformas: «Es verdad, y aun puse ese mismo ejemplo en la vida política. Si por los defectos que llevan en sí las cosas hubieran del todo que quitarse, era preciso destruirlo y quitarlo todo. Cúrese el defecto o padecimiento del cuerpo social; pero no se destruyan las cosas que le han contraído. Esto será propiamente reformar» (14). En contraste, en un momento dado se hace recitar a una niña una coplita en contra de la «libertad de pensar y la licencia en el vivir», de manera que como ley social fundamental se esgrime la defensa del «bien común» antes que prevalezca el interés individual de cada miembro de la sociedad (15).

En todo caso, sí se es perfectamente consciente de que hay que preservar la pureza de la fe y de las prácticas religiosas, denunciando la persecución que soportan los católicos por aquellos que confunden las reformas administrativas con los ataques contra el cuerpo de creencias que han dado unidad religiosa a la Nación. Es por ello que, a través de unas humildes niñas, encarnación de esta Iglesia débil y ultrajada, se advierte contra la secularización progresiva de una sociedad que da la espalda a las enseñanzas del Salvador, $\gg$ nadie saca la cara por Él», y se victimiza a estos nuevos mártires que, como en tiempos del primer cristianismo, soportan las burlas y el desprecio (las niñas son tachadas de «santurronas» y «beatas»), por parte de los defensores de la apostasía más despreciable (16).

La ignorancia habría sido la responsable en último extremo del desembarco arrollador de los malos principios a través de los libros perniciosos que se han leído: las pasiones, las pinturas obscenas, la corrupción en ellos contenida, se han instalado sin dificultad en los entendimientos menos preparados. Saliendo al paso de esta realidad, el objetivo que se persigue es actuar desde la base del problema, ya que se parte de la convicción de que una buena educación en los dogmas conformadores de la fe católica, explicada, razonada y ejemplificada al nivel del entendimiento infantil, podría asegurar el relevo generacional de una cohorte de cristianos aferrados «racionalmente» a la religión que profesan. El ejemplo que puede servir de modelo es el fundamento probado de la doctrina que el Padre Teodoro Almeida expone en Armonía de la razón y la Religión o respuestas filosóficas a los argumentos de los incrédulos, si bien a la hora de 
establecer rangos y jerarquías queda claro que «La luz de la razón es luz divina/ Que a domar las pasiones nos inclina./ Mas alta luz la Religión propone,/ que a la razón excede, y no se opone» (17).

Desde estos presupuestos, el tratado que en principio se pensaba escribir «con un estilo serio y en forma de diálogo entre un incrédulo y un católico», da paso a una representación más creíble que tiene como protagonistas a los personajes que están al cuidado de la escuela de niñas y a éstas mismas, de forma que el intercambio verbal entre la Presidenta de la Junta de Damas, que realiza el trabajo de inspección a través de las siete visitas que contempla el escrito, la Directora de la escuela, responsable directa de la educación, y las propias niñas, que contestan a los requerimientos de ambas, canalizan las opiniones que un tercero, el autor, que se nos presenta como varón y que se vale de este recurso para expresar por boca femenina el modelo de adoctrinamiento que pretende pasar por óptimo (18).

La estructura seguida, puesta de manifiesto en un índice analítico al final de la obra, tiene su desarrollo en las siete visitas, como decimos, que realiza la Presidenta al establecimiento, más una extraordinaria a cargo de dos personajes masculinos, un bibliotecario de Sevilla y un arcediano «sobrino del señor que nos favorece», que son los encargados de dar el visto bueno final al estado de instrucción de las pequeñas. Utilizando este esquema se hace un recorrido por los principales dogmas de la Iglesia, intentando dar una explicación racional y comprensible de la verdad que encierran. Se apuntan «pruebas evidentes de la existencia de Dios», se hace notar la «evidencia de nuestra Santa Religión», se esgrimen «pruebas incontestables» de la naturaleza divina de Jesucristo, de la existencia de otra vida, de la presencia de la divinidad en la especie consagrada, de la Inmaculada Concepción de la Virgen, del misterio de la Santísima Trinidad, del pecado original, del purgatorio, de la resurrección de la carne, etc; al mismo tiempo que se ponen en evidencia, haciendo uso del mismo método racional, las contradicciones que aquejan a las demás religiones monoteístas: judaísmo y mahometismo, además de denigrar intelectualmente al llamado, en ocasiones, «paganismo» o, en otras, «gentilismo».

Todo en forma de diálogo, más bien interrogatorio, entre la directora y presidenta y la niña más espabilada que asiste al centro. Efectivamente, Luisita, que se nos presenta como «la mayor», ya que por su edad y talento «podría servir de pasanta», permanece en el mismo "para que a su ejemplo se vayan formando las demás» (19). El resto de las compañeras, no gozan del protagonismo y carisma que tiene la principal educanda y más bien son utilizadas por el autor para descargar la tensión dialéctica ocasionada por los profundos y enrevesados razonamientos que mantienen a tres bandas la presidenta, la directora y la discípula predilecta. Así Severita, Teresita, Pepita, Dolores, Carmen, Paz, Inocenta, Purificación, Rosa, Jacinta etc, sólo hablan para poner la nota inocente y espontánea que evidencia la edad infantil, sin olvidar que las dificultades de expresión de la «negrita» que asiste a la escuela, coloca la nota de humor que persigue arrancar la risa entre los posibles lectores. El contrapunto a este cuadro 
de personajes bondadosos, lo pone el que es hermano de Luisita, llamado significativamente Silvestre, que representa el espíritu liberal y disoluto que se pretende combatir.

Silvestre es el prototipo de varón descreído de los nuevos tiempos, permeable al influjo de los libros maledicentes y a las corrientes de opinión difundidas en países extranjeros que ha visitado. Su conducta reprobable pasa por la desobediencia y falta de respeto a sus progenitores, sus continuas salidas del espacio doméstico y su asiduidad a bailes, tertulias y saraos son muestras fehacientes de su libertinaje. La proximidad en que se mantiene con respecto a las niñas de la Academia es el trasunto de la difícil convivencia que aqueja al liberalismo y a la Iglesia de los últimos tiempos, y sus continuas apelaciones y denuncias a la mojigatería y beatería de las niñas, representa la presión que la Iglesia está soportando desde que el liberalismo sostiene en el poder a la descendencia de Fernando VII. Al final, la súbita conversión del incrédulo y combativo Silvestre, ocasionada a raíz de una conversación, que no se nos desvela en su pormenores, mantenida con el autor del libro, obra el milagro que la opinión católica todavía espera se opere entre los gobernantes de la nación, de manera que en el texto ( $y$ es lo que fervientemente se desea ocurra en la vida social) el poder político se pliegue a las constantes que marcan la tradición católica del país.

Sin embargo, la esperanza del catolicismo se cifra en el poder de persuasión que ejerza desde la base de la sociedad, desde el interior del seno familiar, la futura mujer instruida sólidamente en los principios de la fe (20). Su fortaleza intelectual, capaz de la réplica razonada a las duras pruebas a que se le someta, además, estará acompañada de una conveniente educación moral que no solamente la identifique por lo que diga, sino también, y fundamentalmente, por lo que haga. El hecho de que la modalidad escolar escogida sea un centro de formación gratuita donde acuden las hijas de las clases populares, pone de manifiesto la intención de modificar la conducta de los más en número y, también, de los más en mostrarse alejados del modelo de vida cristiana que se nos propone (21).

Porque la misión encomendada a la que se instruye para ser correa de transmisión de valores cristianos es muy importante, estamos lejos de estar ante los, cada vez, más residuales testimonios en contra de la educación de la mujer (22). Aunque, es evidente que si bien no se le priva de los dos saberes alfabetizadores, sobre todo de la lectura, sí que se somete a un exhaustivo control el tipo de literatura que puede caer en sus manos. La constante condena de la novela, género que mueve a la fantasía y a la insatisfacción ante una vida anodina que contrasta con las fuertes emociones vividas por sus personajes, se complementa con la recomendación de unos pocos títulos que han de ser leídos una y otra vez hasta interiorizar las enseñanzas que contienen, se trataría de leer poco y leer bien como nos ha advertido Michela de Giorgio (23). Además, los escasos títulos que se barajan enseguida señalan su carga religiosa y moral: máximas y proverbios, sermones, compendios de religión, catecismos y fábulas 
de contenidos ejemplarizantes, constituyen la tipología preferida para su correcta formación (24).

Entre las lecturas recomendadas en el texto: las Lecciones escogidas para los niños es el libro de lectura utilizado en las escuelas de los escolapios a partir de los proverbios de Salomón, trozos de la sabiduría de Vives, Fray Luis de Granada, Fray Luis de León, fábulas de Samaniego... (25); El Tratado de las obligaciones del Hombre, editado por el que fuera preceptor de Fernando VII, Juan de Escoiquiz, en 1821 (26); del Padre portugués Teodoro Almeida, El hombre feliz (27); el conocido popularmente como Turki, por ser obra del capuchino Adeodato Turchi, Homilías predicadas al pueblo de Parma (28) y Madame de Beaumont, Conversaciones familiares de doctrina cristiana, así como El almacén o biblioteca completa de los niños (29).

Por contra, se condenan las novelas, las comedias, los libros de poesía, así como aquellos que alientan prácticas supersticiosas como el libro que habla de la «ventura» y el «sino de cada uno» que trae la «rueda pintada con su letra de molde y todo» (30) y se advierte en contra del obsequio de "pinturas y estampas obscenas», como aquellas que presentan a la Magdalena no «en su estado de penitente, sino en el de disoluta y pecadora por lo deshonesta que está» (31), en tal caso se impele a quemar la representación de una mujer que provoca al «lujo, el escándalo y la impureza», extendiéndose el cuidado en la compra de «abanicos, países (sic), santos y todo lo que sea pintura, adornos y estampas» (32), medios utilizados por aquellos que pretenden la desmoralización y la descatolización de la nación. Pero sin duda, si hay algún autor condenado con rotundidad en el libro este es Juan Jacobo Rousseau, "por quien tanto se desviven los jovencitos del día», al que imprudentemente se parafrasea aludiendo a su Emilio, calificado como libro «malo, lleno de falsos y perversos principios», para seguidamente hacerle blanco de la más absoluta condena (33).

Tan interesante como saber los escasos títulos permitidos es conocer la modalidad que adopta la lectura en el caso de las niñas. Providencial es utilizar el librito de las Meditaciones de la Pasión sacadas de lo preciso para una costura, como su propio nombre indica para recrear el pensamiento durante el tiempo que dure la labor. El Compendio de Religión, es necesario sabérselo «de memoria» de modo que no ha de cansar el «leerlo muchísimas veces» (34), al mismo tiempo que se recomienda tener y releer una vez al año el Hombre feliz (35). La poca capacidad de elección intenta, por tanto, ser compensada con una vuelta monótona al texto, hasta ser capaz de recitarlo en parte sin necesidad de tenerlo presente. Esto no quiere decir que se pretenda un saber autómata, puesto que se reconoce que muchas personas pueden reproducir con exactitud el Catecismo pero sin comprender el significado último de lo que han aprendido a recitar (36).

En cualquier caso, siempre será una lectura autorizada o bien por los padres o por la directora e, igualmente, una lectura vigilada por la madre, puesto que en ella se reconoce a la moldeadora del comportamiento de la niña, y en su 
ausencia, siempre es posible amenazar con la ubicuidad de la divinidad que «está siempre con nosotras viendo lo que hacemos» (37). Lectura y rezo, «de rodillas con manos cruzadas», siempre supervisada por la mirada materna, para evitar el juego o el sueño, también para evitar la distracción en misa, donde se ha de acudir siempre con velo, sin flores en la cabeza y jamás escotadas (38). Porque, desde luego son dignos de censura los padres que no se ocupan de la educación de los hijos y no los entregan para ser instruidos como es debido. De ellos se exige una buena conducta que sirva de ejemplo a los menores. Especialmente vinculada a la madre se encuentra la hija, espejo en el que se mira, ya que «cual es la madre, es la hija», de tal suerte que «por donde salta la cabra, salta la chiva» (39).

Tan peligroso como los malos libros, las malas compañías. De ellas deben las educandas guardarse como del mismísimo diablo se tratase, puesto que la reputación de la mujer proviene del concepto que la sociedad tenga de ella, las amistades inconvenientes tendrán el efecto de señalarla igualmente, ya que «dime con quien andas y te diré quien eres» (40). Huir, especialmente de las muchachas que sólo piensen en cantar, bailar y estarse mirando al espejo, componiéndose y leyendo comedias, novelitas y otros libros así (41). Y, por supuesto, seguir el consejo materno que recibe una de las alumnas, a quien se le recuerda «que los muchachos con los muchachos, y las muchachas con las muchachas» (42). La segregación de los espacios, público para ellos, doméstico para ellas, incluso donde inevitablemente hayan de coincidir, como por ejemplo guardar la debida separación en misa, nos evidencia una posición del autor absolutamente convencida acerca de la diferencia de roles que a ambos sexos compete. Diferencia que, sin embargo, no deriva en inferioridad, puesto que está muy presente para el responsable de estas líneas que la Concepción sin mancha de la Virgen, principio, que no dogma, especialmente defendido por la Iglesia española, dignifica a todo el sexo femenino (43).

La opinión benévola que se mantiene en el bien estar y en el bien hacer, se diluye, en cambio, ante la transgresión del modelo expuesto. Mujer ángel a un paso de la mujer demonio o, como se expresa en el propio texto, aludiendo a la frontera insalvable que se establece entre el prototipo de buena o mala mujer: «La muger es bien y mal/ Tan grande como temido:/ La mala, el mayor trabajo/ La buena, el mayor alivio» (44). No salir se convierte en la mejor garantía para no exponerse a los peligros que acechan, «hacerse caseritas», nada «ventaneras, ni amigas de callejear», resolver el tedio con trabajos manuales, labores o con inocentes diversiones que jamás deben enviciar (45). En el ámbito extradoméstico, rechazados los bailes, tan sólo el cumplimiento religioso justifica una salida, ni siquiera son bien vistas las romerías donde la gente se limita a «divertirse y a profanar los Santuarios con toda clase de excesos y torpezas» (46).

Al igual que no todo se puede leer, no todo se puede cantar y no todo se puede decir. Habrá que tener cuidado en no escandalizar con las tonadillas que expresan «cosas indecentes» (47), en las disputas habrá que manternerse con 
absoluta severidad, para no manifestar «arrebato» (48), y en los dichos no mostrarse vulgar, haciendo uso de «repeticiones y muletillas, sólo propias de gente común y nada civilizada» (49). Se ha de corregir especialmente el empleo de motes y ridículos apodos, como los que usan «la gente soez», a la hora de nombrar a los cristianos. Jamás se ha de decir Lola por Dolores (50) y, sobre todo, saliendo al paso de una moda extranjera que se está imponiendo, jamás llamar con familiaridad a los padres, papá o mamá, y no trastocar el respetuoso Usted, por el «tú, tú»; de los últimos tiempos, antes que eso hacer uso del «español castizo», padre o madre (51).

Todo esto se enseña en la Academia que sostiene la Real Sociedad Económica para niñas pobres que reciben instrucción gratuita, proporcionándoles de balde también los útiles necesarios. Como reza el grabado que se anticipa al texto y que reproduce el interior de la Academia, donde una imagen de la Inmaculada preside un examen a cargo del regente, la directora y la presidenta de la sociedad, «como a niñas os damos instrucciones correspondientes a clase de menores»: Queda claro desde el principio que para estas niñas la Academia es punto de llegada y salida, principio y fin de toda instrucción. La formación religiosa vertebra el tiempo de educación, la Sagrada Escritura se explica en «términos claritos, sencillos y acomodados a su capacidad». De la lectura nos hemos ocupado extensamente y sólo resta hacer notar que los textos utilizados poseen una carga fundamentalmente moral y religiosa. En cuanto a la escritura, escasamente mencionada en el texto, seleccionadas las muestras de Torío o Palomares, despreciando conscientemente el tipo de letra inglesa o francesa en un alarde más que de patriotismo de xenofobia no disimulada en otras partes del texto (52), también se cristianiza en el punto y hora en que se obliga a encabezar la plana con una «crucecita a lo cristiano» (53).

La intención de todo este esfuerzo es enseñar «para ser felices y concurrir a la felicidad de los demás», falta todavía mucho para que se conciba una educación para sí, donde la formación recibida no busque la coartada que sustenta su posición de intermediaria, su yo anulado en beneficio del varón (54). Su natural estado para un futuro próximo, el de casada, implica la enseñanza de todo lo referente a la conducción de la economía doméstica, en donde el ahorro y la previsión serán las virtudes básicas de unas futuras madres cuya humilde condición social no les reserva la administración de un servicio a su cargo, particular que no aparece en todo el tratado, como suele ser común en otros que sí se dirigen a la mujer de alta posición social: «Economía en tu casa/ Tasa tu gasto al bolsillo,/ De suerte que siempre sobre/ Para un caso no previsto» (55). Por el contrario, conscientes de que con toda probabilidad a la salida de la Academia tendrán: que ayudar a conseguir el sustento de sus familias contratándose de doméstica en alguna casa principal de la ciudad, se les recuerda el ascendiente de los amos y superiores sobre aquellos que corren de su cuenta, de modo que se sirvan ser dóciles a las reprensiones que puedan recibir, puesto que, como recuerda la presidenta «el criado hace al amo» y «el criado malo, nunca es bien querido» (56). Los últimos consejos son el de llevar una «Vida honesta y recatada,/Hacer muy pocos remedios, /Y poner todos los medios/ De 
no enfadarse por nada./ La comida moderada,/ Cristiana meditación,/ En Dios gran resignación,/ Ir al campo algunos ratos/De paseo, pocos tratos,/Y continua ocupación» (57).

Las cosas cambian lentamente pero termina por imponerse una nueva realidad que coadyuva a la elevación intelectual de las mujeres. El Siglo de las Luces ha traído definitivamente una nueva concepción del papel que la mujer debe desempeñar en la sociedad y, estando fuera de lugar toda discusión en torno al problema medieval de la posesión del alma y, como derivación de esto, de intelecto por parte del género femenino, se la considera capacitada para incorporarse al aprendizaje de ciertos saberes, eso sí aquellos que determina su naturaleza y con los límites que le impone sus funciones biológicas fundamentales como responsable de la reproducción. Se trata de desarrollar, también lo será para el proyecto educativo liberal, a satisfacción el papel que se le asigna como primera instructora del futuro hombre, por tanto no se debe a una instrucción para sí, que refuerce su independencia, derivada de su derecho como individuo, sino en su calidad de intermediaria y dependiente, como educadora del futuro ciudadano. No obstante, a pesar de estas evidentes limitaciones, el discurso que recomienda el aprendizaje de la lectura y la escritura para las niñas comienza a ser una realidad y será el punto de partida para alcanzar nuevas metas.

\section{NOTAS.}

(1) Comunicación presentada al III Congreso de la Asociación de Historia Contemporánea, bajo el tema «Culturas y civilizaciones», celebrado en Valladolid, del 4 al 6 de julio de 1996.

(2) Sobre el modelo de feminidad en la Edad Moderna, vid. Mariló VIGIL, La vida de las mujeres en los siglos XVI y XVII, Madrid, Siglo XXI, 1986, especialmente pp. 39-61 y $\mathrm{M}^{\mathrm{a}}$ Angeles HERNANDEZ BERMEJO, «La imagen de la mujer en la literatura moral y religiosa de los siglos XVI y XVII», en Norba. Revista de Historia 8/9 (1987-1988), Cáceres, 1990, pp. 175-188. Las autoras tipifican los modelos de comportamiento según se trate del estado de doncella, casada, viuda y la primera estudia también la vida conventual. Por su parte, Marie Catherine BARBAZZA, «L' epouse chrétienne et les moralistes espagnols des XVIè et XVIIè siècles» en Melanges de la Casa de Velázquez, tomo XXUV (1988), pp. 99-136, nos habla del modelo de esposa en Fray Luis, Vives, Pedro Luxán, el padre G. Astete, J. de la Cerda, I. Andueza....autores que consagran como deberes morales de la misma, la obediencia, la fidelidad, el recogimiento, la templanza y el trabajo, a la vez que recuerdan que tiene deberes espirituales que cumplir, una vez ha satisfecho sus obligaciones para con el marido, puesto que «Les moralistes s' accordent tous 'a reconnaitre qu' elle doit avant tout servir un mari avant Dieu, puisque' elle n' est pas religieuse», p. 125. En cualquier caso, el período moderno no presenta una solución uniforme al problema de la educación de las mujeres y puede ser considerado como la etapa 
en la que germina una concepción más amplia en torno a la formación que deben adquirir las mismas. Vid. Martine SONNET, «La educación de una joven», en G. DUBY y M. PERROT, Historia de las mujeres, Vol. III, Madrid, Taurus, 1991, pp. 129-165.

(3) Constituciones de la Escuela Pía que fundó en la ciudad de Cádiz para la enseñanza gratuita de niñas pobres la Sra. $D^{\alpha}$ Mariana de Arteaga Ochoa y Verovia, bajo el nombre y el patrocinio de María SSma del Carmen, Cádiz, Imprenta de D. Juan Ximénez Carreño, 1787: El colegio, sito en el callejón de la Cerería $\mathrm{N}^{\circ} 23$, fundado por disposición testamentaria en 1783, era administrado por patronato episcopal desde 1787 y en el siglo XIX fue servido por el magisterio de una directora, Doña Anastasia Novoa y un regente, hasta que, en 1872 , año en que fue reformado y ampliado, pasó únicamente a depender de las Hermanas pertenecientes a la Orden Carmelita.

(4) Estudian el desarrollo de la educaicón de la mujer dentro del sistema de instrucción pública creado por el liberalismo de la primera mitad del siglo XIX, Geraldine SCANLON, «Revolución burguesa e instrucción femenina», en Nuevas perspectivas sobre la mujer: Actas de las Primeras Jornadas de Investigación Interdisciplinaria, Madrid, Universidad Autónoma, 1982, Tomo II, pp. 163-173; M $^{\mathrm{a}}$ Victoria LOPEZ CORDON, «La situación de la mujer'a finales del Antiguo Régimen (1760-1860)» en Rosa $\mathrm{M}^{\mathrm{a}}$ CAPEL (ed.), Mujer y sociedad en España (1700-1975), Madrid, Ministerio de Cultura, 1982, pp. 47 107; Pilar BALLARIN, «La educación de la mujer española en el siglo XIX», Historia de la Educación, Salamanca, N28, 1989, pp. 245-260. Para el primer tercio del siglo XIX resulta fundamental la consulta de Rosa $\mathrm{M}^{\mathbf{a}}$ CAPEL, $E l$ trabajo y la educación de la mujer en España (1900-1930), Madrid, 1982. La referencia sobre la Biblioteca Nacional está tomada de Myriam CARREÑO RIVERO y Carmen COLMENAR ORZAES, «1837. La Biblioteca Nacional, por primera vez, abre sus puertas a la mujer», Historia de la Educación, Salamanca, N²5, 1986, pp. 177-182.

(5) Proyecto de instalación de una Escuela Gratuita de Niñas, 1 de febrero de 1826, Doc. 17, Archivo Histórico Municipal de Cádiz, en adelante, A.H.M.C.

(6) Reglamento para la Escuela Gratuita de Niñas pobres formado por la Clase de Señoras y aprobado por la Sociedad con las variaciones que aparecen en él, 20 de marzo de 1827, C. 1437, doc. 44. Por su parte, todo parece indicar que el origen de esta asociación femenina pudo estar en la Junta Patriótica de. Damas de Fernando VII, que actuaría y se manifestaría durante la Guerra de Independencia en esta ciudad (el hecho de que a su frente se encontrara la misma Marquesa de Casa-Rábago así parece confirmarlo). Con posterioridad, hay documentos que atestiguan intentos de organización como Clase específica de la Económica entre 1817 y 1819 , pero su definitiva constitución no se produce hasta el 8 de marzo de 1827. La labor desarrollada a partir de entonces se encuentra muy ligada al fomento de la educación femenina, refrendada por una Real Orden de 25 de julio de 1859 del Ministerio de Fomento, en la que se le hace el encargo 
de visitar el conjunto de las academias de niñas de la ciudad. Así, en un Reglamento específico para el funcionamiento de la Junta de Damas que se aprobará el 26 de marzo de 1861, en su Capítulo $1^{2}$ Art. 4, se subrayaba que «el objeto de esta Junta es ocuparse de los ramos de Beneficencia y Fomento de la Instrucción Pública de niñas y párvulos en las escuelas gratuitas de esta ciudad».

(7) Las escuelas públicas de niñas y de párvulos estarían a cargo de las Damas hasta que en el ciclo revolucionario abierto en 1868 renunciaran a proseguir con este cometido, evidenciando divergencias ideológicas con el municipio republicano constituido tras las primeras elecciones recogidas por el sufragio universal. Renuncia de la Junta de Damas a la vigilancia de las escuelas de niñas, octubre de 1869, C. 7270, A.H.M.C.

(8) Traslado de la Escuela Gratuita de Niñas, C. 1437, Doc. 57. A.H.M.C.

(9) Matrícula de la Escuela Gratuita de Niñas de la Sociedad Económica de Cádiz, c. 1437, A.H.M.C., Una panorámica más amplia sobre el funcionamiento de esta escuela, así como del conjunto de la enseñanza primaria en la pasada centuria puede verse en Gloria Espigado Tocino, Aprender a leer y escribir en el Cádiz del Ochocientos, Servicio de Publicaciones de la Universidad de Cádiz, 1996.

(10) El modelo que se señala como inspirador de esta iniciativa es el tratado del Padre Teodoro Almeida, Armonía de la razón y la religión o respuestas filosóficas a los argumentos de los incrédulos, Edición madrileña de 1798, volúmenes $\mathrm{IX}$ y X, que versan sobre la Recreación filosófica o diálogo sobre la filosofia natural para instrucción de personas que no han frecuentado las aulas, Madrid, 1785, 10 vols.

(11) Sobre el conjunto de actuaciones liberales en materia religiosa durante este período, vid. José Manuel CUENCA, La Iglesia Española ante la Revolución liberal, Madrid, Rialp, 1971, especialmente pp. 15-108; Vicente CARCEL ORTI, Política eclesial de los gobiernos liberales españoles (1830-1840), Pamplona, Ediciones de la Universidad de Navarra, 1975, y William J. Callahan, Iglesia, poder y sociedad en España, 1750-1874, Madrid, Nerea, 1989, pp. 145-183.

(12) Alberto RAMOS SANTANA, Cádiz en el siglo XIX. De ciudad soberana a capital de provincia, Madrid, Sílex, 1992, habla de la importancia de la Junta gaditana dentro del movimiento insurreccional habido en 1835 , como defensora de un mayor aperturismo político, identificado con la reposición constitucional de 1812 y la formación de la Milicia Nacional, Vid. pp. 202-207.

(13) Católica infancia, o visitas a la Academia Gratuita del Beaterio, Cádiz, Imprenta de la Viuda e Hijo de Bosch, 1837, p. 129.

(14) Ibídem, p. 229. 
(15) Ibídem, pp. 246-247.

(16) Ibídem, pp. 7, 25, 180 y 182. M² Victoria López Cordón nos ha recordado la importancia de la literatura religiosa en el adoctrinamiento social del XVII y XIX, especialmente interesante en el caso de las mujeres, ya que la transmisión oral de estos contenidos, a través de los sermones, garantizaba la efectividad en la recepción del mensaje, en un contexto de analfabetismo general, donde más del $90 \%$ de las mujeres eran analfabetas, según el censo de 1860. También en los círculos letrados son textos relevantes, dentro de unas constantes que priman la «educación» sobre la «instrucción», reservada, esta última, mayormente para el sexo masculino, mientras, paralelamente, crece la importancia del adoctrinamiento pastoral hacia las mujeres, superando etapas pasadas de mensajes menos diferenciados por sexos. En el XIX, siglo de descreimiento masculino y de feminización de las prácticas religiosas, se constata también, según esta autora, el impacto de un mayor rigorismo moral de influencia burguesa, canalizado a través de formas diferenciadas de piedad según el sexo. $\mathbf{M}^{a}$ Victoria LOPEZ CORDON, «La literatura religiosa y moral como conformadora de la mentalidad femenina (1760-1860)», en VVAA, La mujer en la Historia de España (siglos XVI-XX), Actas de las II Jornadas de Investigación Interdisciplinaria, Madrid, Servicio de Publicaciones de la Universidad Autónoma, 1984, pp. 60-61.

También se han dedicado a analizar la capacidad modeladora de la literatura religiosa, Rufina C. REVUELTA GUERRERO, «La mujer-madre en la oratoria sagrada de la Alta Restauración (1875-1902)» y «La imagen de la mujer a través de los sermonarios de la Alta restauración», comunicaciones presentadas al VI Coloquio de Historia de la Educación, Mujer y educación en España (1868-1975), Santiago de Compostela, 1990, pp. 281-290 y 291-300 respectivamente. Para la etapa inmediatament eposterior vid. Adela OÑA GONZALEZ; "La literatura religiosa como conformadora de un modelo de educación femenina en la Restauración (1875-1931)», en Pilar BALLARIN y Teresa ORTIZ (eds.), Las mujeres en Andalucía. Primer encuentro interdisciplinar de estudios de la mujer, Granada, 1990, Vol. I, pp. 499-507.

(17) Católica infancia:.., pp. 18 y 19.

(18) Estamos ante el viejo subterfugio de dar la palabra a las mujeres en el seno del propio discurso masculino. No son ellos, en este caso, los que hablan sobre ella para ellos, sino que, buscando mayor efectividad ejemplarizante, se deja que ellas se expresen con la máscara del otro sexo, en cualquier caso no se permite que «ellas» se autodefinan. Michèle Crampe Casnabet, «Las mujeres en las obras filosóficas del siglo XVIII», en G. DUBY y M. PERROT, Op. cit., Vol. III, p. 341-342.

(19) Católica Infancia..., pp. 35 y 257. 
(20) «Ya desde las primeras décadas del siglo XIX, muchos autores católicos teorizan una tendencia particular del cristianismo, una tendencia histórica a guiar estas características sentimentales de la feminidad...El alma femenina, distinta y complementaria de la masculina, se convierte, para la Iglesia de la Restauración, en una reserva de recursos civilizadores y de posibilidades de conversión». Michela de GIORGIO, «El modelo católico», en Historia de las mujeres...Op. cit., Vol. IV, p. 184.

(21) «Este establecimiento es en todo consiguiente a la clase de niñas que a él asisten: son de la menesterosa, y se reduce a formarlas muy cristianas y diestras en las labores de sus casas, que ciertamente están bien lejos de todo lo que toca a el lujo», Católica Infancia..., p. 50. No será la única vez que se apele con esta intención a la mujer del pueblo, otra iniciativa llevada a cabo también en Cádiz, hacia 1877, por el padre Francisco A. Medina, pretendía «moralizar al barrio de la Viña», uno de los más populares de la ciudad, a través de la acción educativa sobre sus adultas, ya que, pensaba el presbítero, «la mujer es la llave de la familia y su influencia es eficacísima cuando se trata de reformarla", Actas Capitulares del Ayuntamiento de Cádiz, 1 de diciembre, p. 6 y 15 de diciembre de 1876, p. 15. Respuesta a la solicitud presentada por el Prebsítero Francisco de A. Medina, 3 de enero de 1877, C. 2038, Exp. 27, A.H.M.C.

(22) Dentro del ciclo revolucionario abierto en 1789, el demoliberalismo naciente termina por desarrollar estrategias de exclusión para no ser consecuente con los derechos individuales que lo inspiran, como nos recuerda Geneviève Fraisse. Así, no nos puede extrañar que sea un seguidor de Babeuf, Silvain Marechal, el que se apresure a redactar un Proyecto de ley que prohíba aprender a leer a las mujeres (1801), rápidamente contestado por M.A.J. Gacon-Dufour y por A. Clément Hémery, la primera recibiéndolo como una broma, la segunda como una afrenta al sexo femenino. Geneviève FRAISSE, Musa de la razón. La democracia excluyente y la diferencia de los sexos, Madrid, Cátedra, 1991.

(23) M. de GIORGIO, Op. cit., p. 196.

(24) Porque «las niñas que leen buenos libros, son buenas y salen instruidas; $y$ las que leen libros malos o de mero pasatiempo, se hacen malas o poco substanciales en sus acciones, producciones y discursos», Católica infancia...p. 22, y es que «...muchas no aprenden, o se les olvida leer; otras dejan estos libros tan indispensables y se avanzan sin dirección a toda clase de novelas, poesías y libros los más perjudiciales, resultando de esto el pervertirse y aun descatolizarse», Ibidem, p. 33

El Diccionario de Pedagogía de Mariano Carderera y Potó, compendio del saber pedagógico decimonónico (fue editado en Madrid en 1854 y reeditado en 1883) y obra de obligada consulta en nuestras Escuelas Normales de maestros y maestras, dedica una voz a desarrollar los efectos perniciosos que sobre la educación, especialmente las niñas, causa la novela. Entendida como un género que tiene la facultad de reproducir las costumbres sociales, pero también de 
transgredirlas, será considerada por la mayoría de los moralistas como la modalidad literaria más perjudicial para la mujer, en la medida en que ayude a generar inconformismo y aliente actuaciones perturbadoras del orden familiar. Entre otras opiniones autorizadas el Diccionario cita a la escritora y pedagoga francesa Mme. Campan (1752-1822), educadora de las princesas reales, al servicio de María Antonieta, y, más tarde, directora con napoleón del centro de educación femenino que éste erigiera en 1807. Según su opinión en las novelas «la imagen del marido es bella y heroica y si el marido que le toca no es bien parecido, como sucede normalmente, a aquel modelo, desgraciadamente podrá suceder que ella siga buscando otro igual, aún después de casada» (Vid. Novela, Vol. IV, p. 107).

(25) Lecciones escogidas para los niños que aprenden a leer en las Escuelas Pías. Corregidas y aumentadas por su actual rector el P. Pascual Suárez del Dulce Nombre de María, M. Imprenta Real, 1815.

(26) Conoce múltiples ediciones posteriores, tras la de Barcelona en 1821, Zaragoza, 1822, Córdoba, 1836, Cuenca, 1845, Segovia, 1854, Córdoba y Málaga, 1857, etc...

(27) Teodoro Almeida, El hombre feliz, independiente del mundo y de la fortuna: o arte de vivir contento en cualesquieras trabajos de la vida, Traducido del portugués por José Francisco Monserrate Urbina, Madrid, Román, 1785 y 1786, 3 vols. Conoce una difusión importante a través de numerosas ediciones.

(28) Conjunto de sermones predicados hacia 1789 y publicado en 2 volúmenes en Barcelona en 1795. El primer volumen contiene pláticas sobre el amor de Dios y del prójimo, sobre la Asunción de María, sobre el culto exterior, sobre el cotejo de la Filosofía del Evangelio con la del siglo, sobre los consejos evangélicos, sobre la lectura de los libros prohibidos, sobre el respeto que se debe a la Iglesia Católica, sobre los bienes temporales de la misma y sobre la reverencia que se debe a los sagrados templos. El segundo, habla de la libertad cristiana, de la igualdad evangélica, hace una defensa de la vida contemplativa, versa también sobre la autoridad, condena el amor a la novedad, la tolerancia en los asuntos de religión, el culto a las reliquias, etc.

(29) Jeanne-Marie Leprince, Mme. de Beaumont (1711-1780), Conversaciones familiares de doctrina cristiana, Traducida por Miguel Ramos y Linacero, Madrid, 1773, 2 vols., reimp. en Madrid, en 1778 y ediciones ya en el XIX; Almacén o Biblioteca completa de los niños Imp. de P. Baro López, 1790, 4 vols. Esta última es su obra más conocida, escrita en 1757, en la que se incluye el célebre cuento de la Bella y la Bestia. También es autora de un Almacén de las señoritas adolescentes o diálogos de una sabia directora con sus nobles discípulas, Trad. de Plácido Barco López, Madrid, 1787, 4 vols. (se conocen ediciones de 1804,1815 y 1829 ).

(30) Católica Infancia, p. 55. 
(31) Ibídem, p. 194.

(32) Ibídem, p. 195.

(33) Ibídem, p. 13 y ss.

(34) Ibídem, p. 11.

(35) Ibídem, p. 200.

(36) Ibídem, p. 34.

(37) Ibídem, p. 191.

(38) Ibídem, p. 3.

(39) Ibídem, p. 188.

(40) Ibídem, p. 20. Lo expresaba nítidamente Rousseau cuando definía al sexo femenino como ser de la apariencia: «su honor no está solamente en su conducta, sino en su reputación...el hombre, en su actuación, sólo depende de él y puede desafiar al juicio público; pero la mujer al actuar bien sólo ha cumplido la mitad de su misión y lo que se piense de ella no le importa menos que lo que en efecto sea...», J.J. Rousseau, Emilio o de la educación, Madrid, EDAF, 1985, p. 420.

(41) Católica Infancia..., p. 22.

(42) Ibidem, p. 94.

(43) Ibídem, p. 161. Frente a las creencias judías y, más tarde, protestantes, la teología católica defendió este misterio que implicaba la pureza ante el pecado de la Madre de Dios. Será Carlos III el que eleve una petición formal en este sentido al Papa Clemente XIII en 1760, posteriormente, el Concilio Vaticano I establecerá el dogma a mediados de la centuria siguiente (1854). Igualmente, su virginidad, así como su asunción en cuerpo y alma a los cielos fueron temas especialmente defendidos por los teólogos y la monarquía española. Isabel II, arropada por obispos y teólogos nacionales, trabajó a partir de 1863 en favor del misterio de la Asunción que fue establecido en 1950.

(44) Católica Infancia..., p. 219.

(45) Ibidem, p. 57-58.

(46) Ibidem, p. 176.

(47) Ibidem, p. 102. 
(48) Ibidem, p. 117.

(49) Ibidem, p. 191.

(50) Ibidem, p. 209.

(51) Ibidem, p. 62-64.

(52) Ibidem, p. 50.

(53) Ibidem, p. 259.

(54) Dentro del sistema general de enseñanza, la educación de las mujeres, que conlleva el reconocimiento de este estrecho pero progresivo acceso a los distintos niveles formativos, constituye uno de los instrumentos básicos para la emancipación histórica de las mismas. Otra cosa es que, en consonancia con el perfil que la sociedad burguesa tiene en torno a las capacidades y funciones de éstas, se atienda a un modelo pedagógico y curricular sesgado que responda a estas especificidades, de manera que la escuela haya servido fundamentalmente para apuntalar las diferencias en los roles que la sociedad demanda a cada sexo. Esta idea puede verse ampliada en Pilar BALLARIN DOMINGO, «La construcción de un modelo educativo de utilidad doméstica», en Historia de las mujeres...Op. cit., vol. IV, pp. 600 y ss. A parecidas conclusiones llega Geraldine M. SCANLON, en «La mujer y la instrucción pública: de la Ley Moyano a la II República», en Historia de la Educación, Salamanca, №6, enerodiciembre, 1987, pp. 193-207.

(55) Católica Infancia..., p. 220.

(56) Ibidem, p. 132-133.

(57) Ibidem, p. 251. 